\title{
Possible Chemosensitizing and Potent Anticancer Effects of D-Fraction in Combination with Vitamin C on Three Prevalent Urologic Cancer Cells
}

\author{
Drew Freilich, Eric Moskowitz, Nicholas Feuer, Muhammad Choudhury, John Phillips, \\ Sensuke Konno*
}

Department of Urology, New York Medical College, Valhalla, USA

Email: 'Sensuke konno@nymc.edu

Received 25 October 2014; revised 20 November 2014; accepted 11 December 2014

Academic Editor: Yu Cao, The Scripps Research Institute, USA

Copyright (C) 2014 by authors and Scientific Research Publishing Inc.

This work is licensed under the Creative Commons Attribution International License (CC BY).

http://creativecommons.org/licenses/by/4.0/

(c) ()) Open Access

\section{Abstract}

Chemotherapy is currently one of the most common therapeutic options for cancer patients despite the poor efficacy with considerable side effects. We then examined if D-fraction (DF), a bioactive mushroom extract, could potentiate (poor) anticancer effects of those drugs in vitro. Three urologic cancers, prostate, bladder, and kidney cancers, were tested with various chemotherapeutic drugs and their combinations with DF. Compared to individual drugs alone, combinations of drugs and DF have improved anticancer activity, resulting in the significant $(P<0.05)$ cell viability reduction in all three cancer cells. As vitamin C (VC) has been postulated to potentiate the bioactivity of DF, this possibility was also examined. The specific combination of DF $(300 \mu \mathrm{g} / \mathrm{ml})$ and VC $(200 \mu \mathrm{M})$ indeed led to the drastic $(\geq 90 \%)$ viability reductions in all three cancer cells. To have a better understanding of such a profound viability reduction, the effect of DF/VC combination on cell cycle was examined next. Cell cycle analysis indicated that this combination induced a $G_{1}$ cell cycle arrest, which was also confirmed by the down-regulation of specific cell cycle regulators (CDK2, CDK4, and cyclin $\mathrm{D}_{1}$ ) detected on western blots. Moreover, it was crucial to address if the DF/VC-induced viability reduction could be also linked to apoptosis. Western blot analysis revealed that anti-apoptotic bcl-2 was down-regulated while pro-apoptotic Bax was up-regulated with DF/VC combination in all cancer cells, indicating induction of apoptosis. Therefore, the DF/VC combination could ultimately induce apoptosis, accounting for the severe cell viability reduction. In conclusion, DF appears to be a promising agent with chemosensitizing effect, enhancing the

\footnotetext{
${ }^{*}$ Corresponding author.
}

How to cite this paper: Freilich, D., Moskowitz, E., Feuer, N., Choudhury, M., Phillips, J. and Konno, S. (2014) Possible Chemosensitizing and Potent Anticancer Effects of D-Fraction in Combination with Vitamin C on Three Prevalent Urologic Cancer Cells. Journal of Cancer Therapy, 5, 1402-1411. http://dx.doi.org/10.4236/jct.2014.514142 
efficacy of chemotherapeutic drugs, and its combination with VC exhibits a potent anticancer effect, which is far superior to any combinations of drugs and DF tested in three prevalent urologic cancer cells.

\section{Keywords}

\section{Mushroom Extract, Chemosensitizing Effect, Anticancer Effect, Combination Therapy, Urologic Cancers}

\section{Introduction}

Three prevalent urologic cancers such as prostate, bladder, and renal cell carcinomas demand the safer and more effective therapeutic modalities. Prostate cancer is the most common malignancy in elderly men and the second leading cause of male cancer death in the United States [1]. Although the initial response to primary hormonal therapy usually shows a good prognosis, the cancer remains refractory and most ( $80 \%)$ of these patients experience a progression of their cancers to a refractory state (relapse) within a few years [2]. Unfortunately, current conventional therapies for such hormone-refractory disease are rather disappointing; androgen ablation, brachytherapy, external radiotherapy, and chemotherapy have not been effective [2] [3]. Bladder cancer is the second most common urologic malignancy next to prostate cancer [4] and more than $90 \%$ of bladder cancers are transitional cell carcinoma (TCC) [5]. Approximately 70\% of TCCs present superficial bladder tumor and the rest of $30 \%$ include invasive or metastatic disease [6]. Although endoscopic transurethral resection (TUR) is a primary therapy, $60 \%-70 \%$ of patients will yet recur and about $25 \%$ progress to invasive disease within 5 years [5]. Renal cell carcinoma (RCC) is the sixth most common cancer [7] and nearly 30\% of patients would present metastatic disease at the time of diagnosis [8]. Although the primary treatment for localized RCC is nephrectomy, $30 \%-40 \%$ of patients would have a recurrence leading to a metastatic disease with the 5-year survival rate of $<10 \%$ [9] [10].

Among those therapeutic modalities described, chemotherapy is yet one of the common therapeutic options that has been often applied to three urologic cancers, although the outcomes have been rather disappointing or unsatisfactory with the poor efficacy and palpable side effects [3] [5] [9]. In addition, these urologic cancers are also known to have the drug-resistant nature against chemotherapeutic drugs [11]. These facts then sturdily encourage and demand exploration of alternative modalities that may improve the outcomes with few side effects [12].

As we have been exploring combination therapy using chemotherapeutic drugs and natural agents extracted from herbs, plants, mushrooms, seeds, fruits, etc., we have come across a bioactive mushroom extract, D-fraction (DF). This DF is the protein-bound polysaccharide or proteoglucan, consisting of a bioactive component known as $\beta$-glucan (Figure 1) with a molecular weight of $\sim 1 \times 10^{6}$ dalton [13]. Characteristically, it has acid-insoluble, alkali-soluble and a hot water-extractable nature [13]. Since DF has been commercially available for a variety of medical and scientific research, a number of such studies conducted in past 30 years confirmed its immunomodulatory and antitumor activities with few side effects in vitro and in vivo [14]-[17]. For example, antitumor

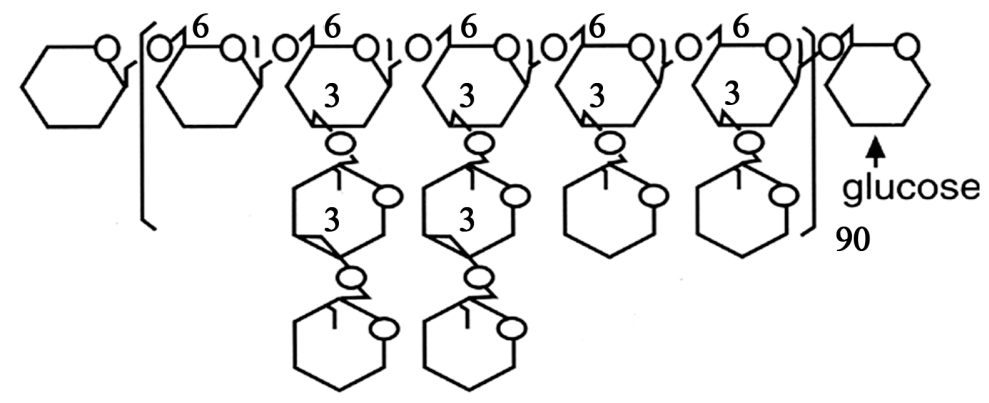

Figure 1. Structure of DF (with $\beta$-linkages). 
activity of DF has been shown in tumor-bearing mice through activation of various immune effectors such as macrophages, cytotoxic T-lymphocytes, natural killer cells, etc. [14] [15]. Thus, DF is an interesting natural agent that deserves further studies on its antitumor/anticancer activity.

Accordingly, we investigated if combination of chemotherapeutic drugs and DF would improve the poor drug efficacy on three urologic cancer cells in vitro. In addition, as vitamin C (VC) has been proposed to potentiate the bioactivity of DF [18], we tested if combination of DF and VC would exhibit any (improved) anticancer effect. To explore the underlying mechanism(s) of the improved anticancer activities by drug/DF or DF/VC combinations, the cell cycle regulation was also examined. Moreover, whether the increased cell viability reduction by specific combinations would be associated with apoptosis was further assessed. More details and notable findings in this study were described herein.

\section{Materials and Methods}

\subsection{Cell Culture}

The three human urologic cancer cell lines, prostate cancer PC-3, bladder cancer T24, and kidney cancer ACHN, were obtained from the American Type Culture Collection (ATCC; Manassas, VA). They were maintained in RPMI 1640 medium containing 10\% fetal bovine serum, penicillin (100 units/ml), and streptomycin $(100 \mu \mathrm{g} / \mathrm{ml})$ at $37^{\circ} \mathrm{C}$. Chemotherapeutic drugs were purchased from Sigma-Aldrich (St. Louis, MO) and a standardized Dfraction (DF; 30\% of the content) was a gift from the manufacturer (Mushroom Wisdom, Inc., East Rutherford, NJ). This DF is commercially available for personal use or research purpose. For experiments, specific drugs being clinically used were tested: paclitaxel (PTX) was tested in PC-3 cells; cisplatin (CPL) in T24 cells; and 5 -fluorouracil (5FU) in ACHN cells. Three cancer cells were seeded at the initial cell density of 1 or $2 \times 10^{5}$ cells $/ \mathrm{ml}$ in 6-well plates or T-75 flasks and treated with varying concentrations of each drug assigned or combinations of these drugs and DF. They were also separately treated with combination of DF and vitamin C (VC). Cell viability was then assessed by MTT assay at specified times.

\subsection{MTT Assay}

Cell viability was determined by MTT (3-[4,5-dimethylthiazol-2-yl]-2,5-diphenyl-tetrazolium bromide) assay following the vendor's protocol (Sigma-Aldrich, St. Louis, MO). This system is based on the conversion of the water-soluble MTT to an insoluble purple formazan through mitochondrial dehydrogenases in viable cells. Briefly, at the harvest time, MTT reagent $(1 \mathrm{mg} / \mathrm{ml})$ was added to the 6-well plate, which was then incubated for $3 \mathrm{~h}$. After removing MTT, DMSO (dimethyl sulfoxide) was added to each well to dissolve the formazan crystals (with purple color). Absorbance of formazan solution was read in a microplate reader and cell viability was expressed by the \% relative to the control reading (100\%).

\subsection{Cell Cycle Analysis}

Cell cycle phase distributions were determined on a FACScan flow cytometer (Becton-Dickinson) equipped with a double discrimination module. Control or agents-treated cells $\left(\sim 1 \times 10^{6}\right.$ cells per condition) were resuspended in $500 \mu \mathrm{l}$ of propidium iodide solution ( $20 \mu \mathrm{g} / \mathrm{ml}$ propidium iodide, $0.2 \mathrm{mg} / \mathrm{ml}$ RNase, $0.2 \mathrm{mg} / \mathrm{ml}$ EDTA, $0.5 \%$ nonidet $\mathrm{p}-40$ ) and incubated for $1 \mathrm{~h}$ at room temperature in the dark. Approximately 10,000 nuclei from each sample were analyzed on a flow cytometer, and CellFit software was used to quantify cell cycle compartments to estimate the $\%$ of cells distributed in the different cell cycle phases.

\subsection{Western Blot Analysis}

The procedures essentially followed the protocol described elsewhere [19]. Briefly, cell lysates were obtained from control and agent-treated cells by "freeze-thaw" in liquid nitrogen. An equal amount of cell lysates (7 $\mu \mathrm{g}$ ) was subjected to $10 \%$ SDS-polyacrylamide gel electrophoresis and transferred to a nitrocellulose membrane. The blot (membrane) was incubated for 90 min with the primary antibodies against, CDK2, CDK4, cyclin $\mathrm{D}_{1}$, bcl-2, or Bax (Santa Cruz Biotechnology, Santa Cruz, CA), followed by 30-min incubation with the appropriate secondary antibody conjugates. The specific immunoreactive protein bands were then detected by chemiluminescence following the manufacturer's protocol (Kirkegaard and Perry Laboratories, Gaithersberg, MD). 


\subsection{Statistical Analysis}

All data were presented as mean \pm SD (standard deviation), and statistical differences between groups were assessed with either one-way analysis of variance (ANOVA) or the unpaired Student's $t$ test. Values of $\mathrm{P}<0.05$ were considered to indicate statistical significance.

\section{Results}

\subsection{Effects of Chemotherapeutic Drugs Alone or Their Combinations with DF on Cell Viability of Three Urologic Cancer Cells}

Three different urologic cancer cells, prostate cancer PC-3, bladder cancer T24, and kidney cancer ACHN cells, were treated with PTX $(0-8 \mathrm{nM})$, CPL $(0-80 \mu \mathrm{M})$, and 5FU $(0-150 \mathrm{ng} / \mathrm{ml})$, respectively. Additionally, these cancer cells were also treated with combinations of each drug and DF $(300 \mu \mathrm{g} / \mathrm{ml})$ : PC-3 cells were treated with PTX/DF, T24 cells with CPL/DF, and ACHN with 5FU/DF combinations. As $300 \mu \mathrm{g} / \mathrm{ml}$ of DF by itself has been shown to have little effects on all three cancer cells (Table 1), any improved effects of drug/DF combinations can be properly assessed using this DF concentration. After $72 \mathrm{~h}$, all cancer cells were subjected to MTT assay for determining cell viability since anticancer effects of drugs alone or drug/DF combinations can be assessed by the reduction (\%) in cell viability relative to controls (100\%).

The results showed that no cell viability reduction was seen in any cancer cells at any given drug concentrations (Figures 2(a)-(c)). However, combinations of PTX, CPL, or 5FU and DF (300 $\mu \mathrm{g} / \mathrm{ml})$ led to a maximum $45 \%, 42 \%$, and $49 \%$ cell viability reduction in PC-3, T24, and ACHN cells, respectively (Figures 2(a)-(c)). Thus, these results suggest that DF may sensitize those chemotherapeutic drugs to a certain extent, enhancing their anticancer activities on cancer cells (i.e. a chemosensitizing effect). For a better understanding, Table 2 summarizes how much (\%) anticancer activities of drugs alone were increased with DF, by calculating the differences in the cell viability reductions (\%) induced by either drug alone or drug/DF combination. It indeed shows that anticancer effects of PTX, CPL, and 5FU are increased by $20 \%, 35 \%$, and $43 \%$ with DF in PC-3, T24, and ACHN cells, respectively.

\subsection{Synergistic Potentiation of Anticancer Effect of DF and VC Combination}

VC is a well-known beneficial nutritional supplement, which has been extensively studied for a potential role in cancer prevention and treatment [20] [21]. It has also been implied to enhance the bioactivity of DF [18]. We

Table 1. Effects of sole DF or VC on cell viability of three urologic cancer cells.

\begin{tabular}{|c|c|c|c|c|}
\hline & & \multicolumn{3}{|c|}{ Cell viability (\%) at $72 \mathrm{~h}$} \\
\hline & & PC-3 & T24 & $\mathrm{ACHN}$ \\
\hline \multirow[t]{6}{*}{ DF ( $\mu \mathrm{g} / \mathrm{ml}):$} & 0 & 100 & 100 & 100 \\
\hline & 100 & 100 & 100 & 100 \\
\hline & 200 & 100 & 100 & 100 \\
\hline & 300 & 100 & 100 & 100 \\
\hline & 500 & $\sim 80^{*}$ & $\sim 80^{*}$ & $\sim 90$ \\
\hline & 700 & $\sim 50^{*}$ & $\sim 55^{*}$ & $\sim 60^{*}$ \\
\hline \multirow[t]{6}{*}{ VC $(\mu M):$} & 0 & 100 & 100 & 100 \\
\hline & 100 & 100 & 100 & 100 \\
\hline & 200 & 100 & 100 & 100 \\
\hline & 300 & $\sim 90$ & $\sim 80^{*}$ & $\sim 75^{*}$ \\
\hline & 500 & $\sim 65^{*}$ & $\sim 60^{*}$ & $\sim 50^{*}$ \\
\hline & 700 & $\sim 20^{*}$ & $\sim 10^{*}$ & $\sim 10^{*}$ \\
\hline
\end{tabular}

DF: D-fraction; VC: vitamin C. ${ }^{*} \mathrm{P}<0.05$. 


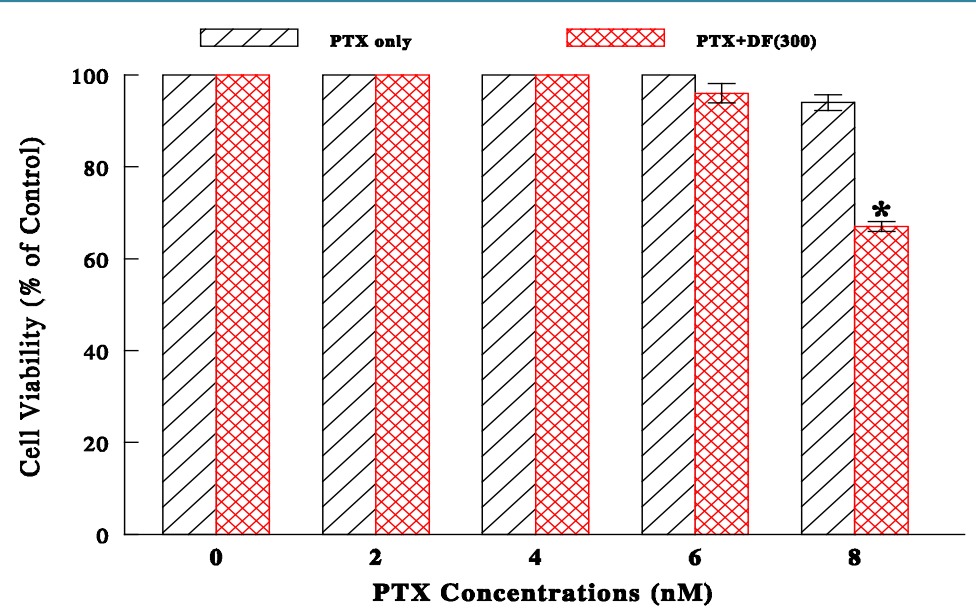

(a)

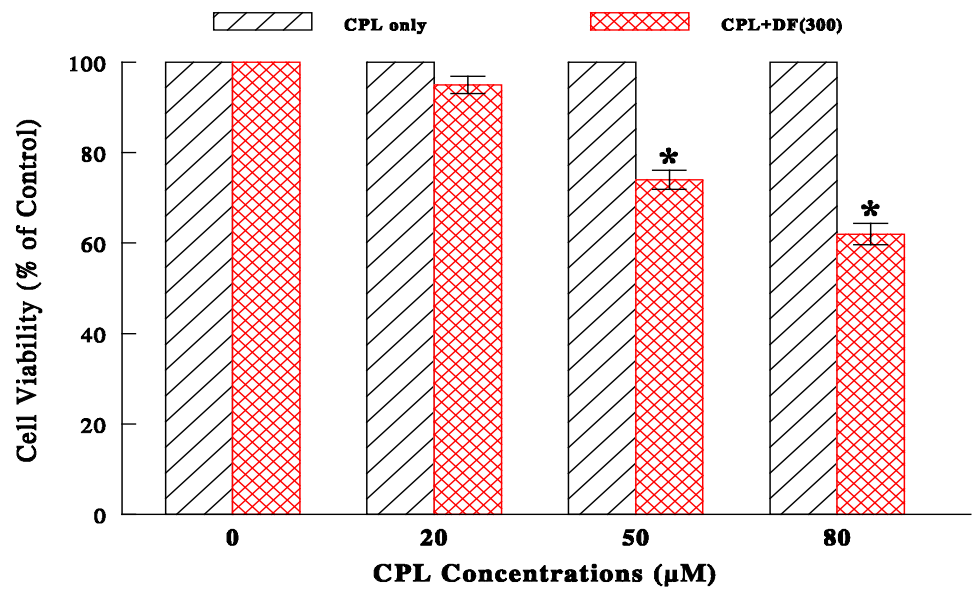

(b)

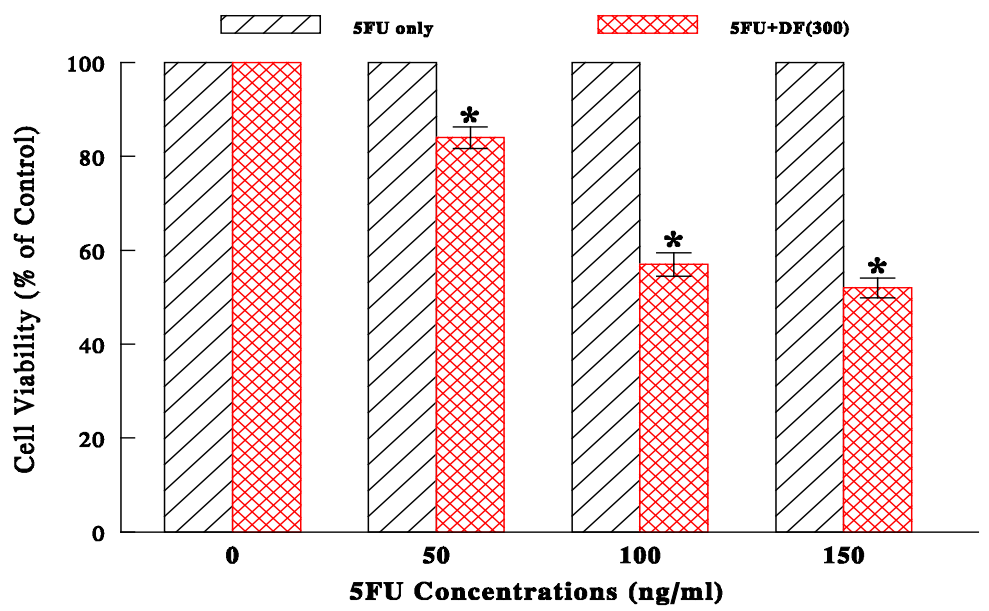

(c)

Figure 2. Effects of chemotherapeutic drugs alone or in combination with DF on cell viability. Prostate cancer PC-3 (a), bladder cancer T24 (b), and kidney cancer ACHN cells (c) were treated with PTX (0 - 8 nM), CPL $(0-80 \mu \mathrm{M})$, and 5FU $(0-150 \mathrm{ng} / \mathrm{ml})$, respectively. Separately, these cells were also treated with combinations of each drug and DF (300 $\mu \mathrm{g} / \mathrm{ml})$. At $72 \mathrm{~h}$, cell viability was assessed and expressed by the percent (\%) of viable cells relative to controls $(100 \%)$. The data are mean \pm SD (standard deviation) from three separate experiments ( $\mathrm{*}$ < 0.05 compared with respective controls). (a) PC-3 cells; (b) T24 cells; (c) ACHN cells. 
Table 2. Improved anticancer activities of chemotherapeutic drugs with DF.

\begin{tabular}{cc}
\hline Cancer cell lines & Increase (\%) in anticancer effects by drug/DF combination \\
\hline PC-3 & $\mathbf{2 0 \%}$ increase (with PTX+DF compared to PTX alone) \\
T24 & $\mathbf{3 5 \%}$ increase (with CPL+DF compared to CPL alone) \\
ACHN & $\mathbf{4 3 \%}$ increase (with 5FU+DF compared to 5FU alone) \\
\hline
\end{tabular}

DF: D-fraction; PTX: paclitaxel; CPL: cisplatin; 5FU: 5-fluorouracil.

then examined if combination of DF and VC could exhibit any anticancer activity against these cancer cells. Although they were initially cultured with combination of DF (300 $\mu \mathrm{g} / \mathrm{ml})$ and VC $(200 \mu \mathrm{M})$ for $72 \mathrm{~h}$, cell viability was assessed at $24 \mathrm{~h}$ because this combination required only $24 \mathrm{~h}$ to cause the severe cellular effects. In addition, neither DF (300 $\mu \mathrm{g} / \mathrm{ml})$ nor VC $(200 \mu \mathrm{M})$ alone was found to have any effects (Table 1$)$. As it was also possible that combinations of these drugs and VC might show some positive effects, PC-3, T24, and ACHN cells were treated with combinations of PTX $(8 \mathrm{nM})$, CPL $(80 \mu \mathrm{M})$, or 5FU $(150 \mathrm{ng} / \mathrm{ml})$ at the highest concentrations and VC $(200 \mu \mathrm{M})$ for $72 \mathrm{~h}$, respectively.

MTT assays showed that the DF/VC combination resulted in a drastic $\geq 90 \%$ cell viability reduction in all three cancer cells in $24 \mathrm{~h}$, whereas any combinations of drugs (PTX, CPL, or 5FU) and VC had little effects even after $72 \mathrm{~h}$ (Figure 3). For comparison, the additional data from each drug alone and in combination with DF (300 $\mu \mathrm{g} / \mathrm{ml})$ in all cancer cells are also shown in Figure 3. Therefore, unlike DF, VC failed to improve or enhance the drug efficacy but its combination with DF became highly potent, inducing the greatest cell viability reduction $(\geq 90 \%)$ that was far more profound than the viability reductions induced by any drug/DF combinations. Furthermore, these results suggest that DF and VC may work synergistically to induce such a severe cell viability reduction since the given concentrations of DF (300 $\mu \mathrm{g} / \mathrm{ml})$ and VC $(200 \mu \mathrm{M})$ by itself had little effects (Table 1).

\subsection{Effect of DF/VC Combination on Cell Cycle}

To understand how this DF/VC combination would induce such an extensive viability reduction, its possible effect on cell cycle was then examined. After 24-h treatment with the DF/VC combination, three cancer cells were subjected to cell cycle analysis to determine the cell number (\%) in each cell cycle phase. These results showed that the DF/VC combination led to a significant $(\mathrm{P}<0.05)$ increase in $\mathrm{G}_{1}$-phase cell number concomitant with a significant $(\mathrm{P}<0.05)$ decrease in S-phase cell number in all three cancer cells (Figure 4). This cell accumulation in the $\mathrm{G}_{1}$ phase is known as a $\mathrm{G}_{1}$ cell cycle arrest [22]. Thus, the DF/VC combination appears to specifically halt the $\mathrm{G}_{1}-\mathrm{S}$ phase progression, subsequently leading to the cell viability reduction.

\subsection{Effects on Specific Cell Cycle Regulators Following DF/VC Treatment}

For confirmation of a $G_{1}$ cell cycle arrest by the DF/VC combination, the effects of this combination was assessed on the specific cell cycle regulators for the $\mathrm{G}_{1}$-S phase transition [22]. Three cancer cells were treated with combination of DF $(300 \mu \mathrm{g} / \mathrm{ml})$ and VC $(200 \mu \mathrm{M})$ for $24 \mathrm{~h}$ and subjected to western blot analysis on three $\mathrm{G}_{1}$-specific cell cycle regulators, CDK2, CDK4, and cyclin $\mathrm{D}_{1}$. The expressions of all three regulators were significantly reduced or down-regulated (compared with controls) by the DF/VC treatment in all three cancer cells, but only the results of PC-3 cells are shown here as a representative (Figure 5). Such down-regulations of these specific regulators in PC-3, T24, and ACHN cells are indeed indicative of a $\mathrm{G}_{1}$ cell cycle arrest. Thus, these findings suggest that the DF/VC combination primarily targets the specific cell cycle phases and induces a $\mathrm{G}_{1}$ cell cycle arrest in three urologic cancer cells, partly accounting for the resulting cell viability reduction.

\subsection{Induction of Apoptosis by DF/VC Combination}

It was critical to also learn if the DF/VC-induced cell viability reduction might be linked to apoptosis (programmed cell death). Three cancer cells were exposed to combination of DF (300 $\mu \mathrm{g} / \mathrm{ml})$ and VC (200 $\mu \mathrm{M})$ for $24 \mathrm{~h}$ and analyzed for two key apoptosis regulators, bcl-2 and Bax [23]. Western blot analysis then revealed that bcl-2 expression was down-regulated while Bax expression was up-regulated in all three cancer cells with the $\mathrm{DF} / \mathrm{VC}$ combination (Figure 6). As bcl-2 is known as an anti-apoptotic regulator while Bax is a pro-apoptotic 


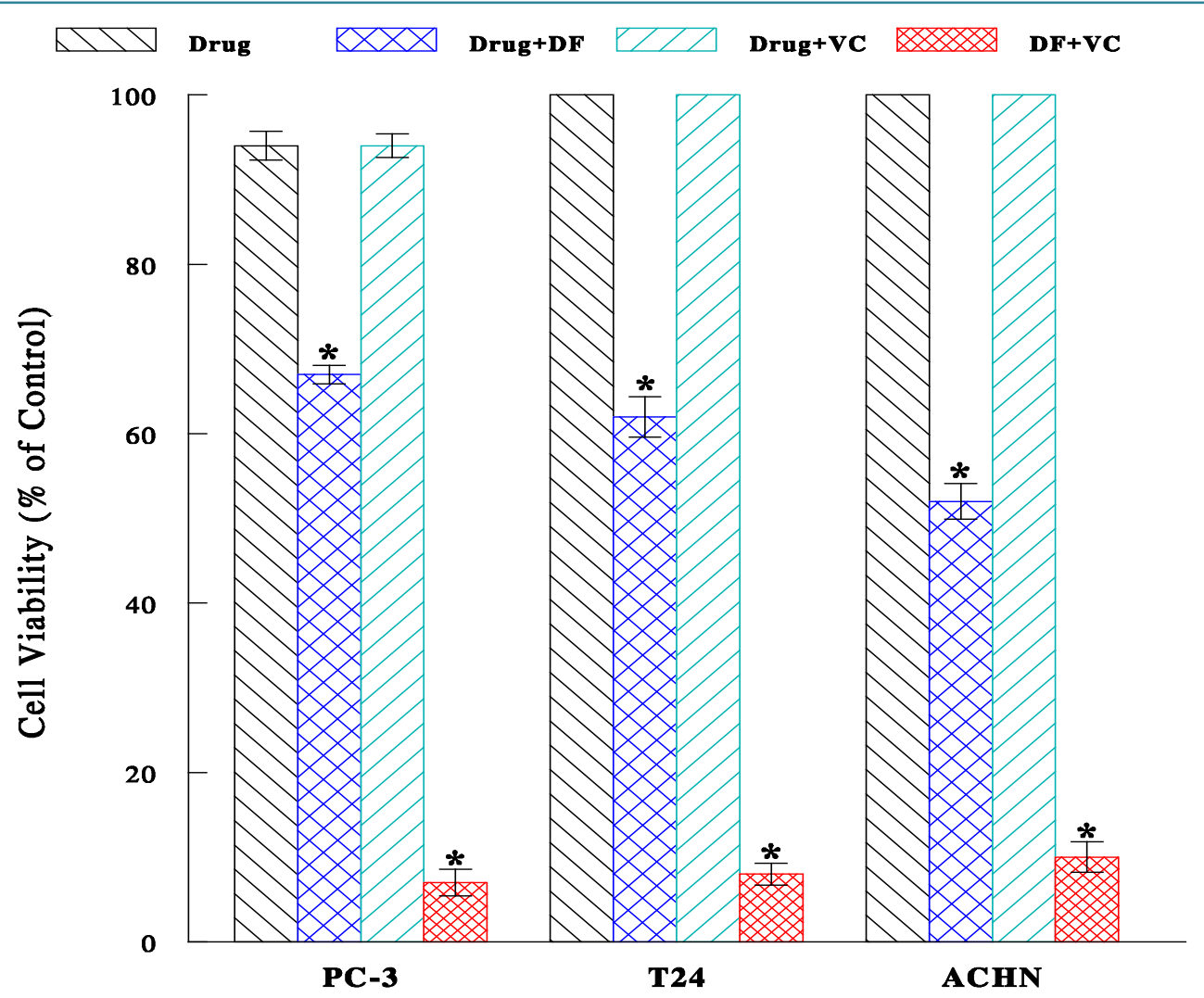

Figure 3. Effects of combinations of drugs and VC or DF and VC on cell viability. PC-3, T24, and ACHN cells were treated with combinations of PTX, CPL, or 5FU and DF, respectively, or with DF/VC combination. Cell viability was assessed at indicated times by MTT assays and expressed by the $\%$ of controls. All data are mean \pm SD from three independent experiments $\left({ }^{*} \mathrm{P}<0.01\right.$ compared with respective controls).

$\square \mathrm{G} 1 \quad \square \mathrm{S} \quad \square \mathrm{G} 2 / \mathrm{M}$

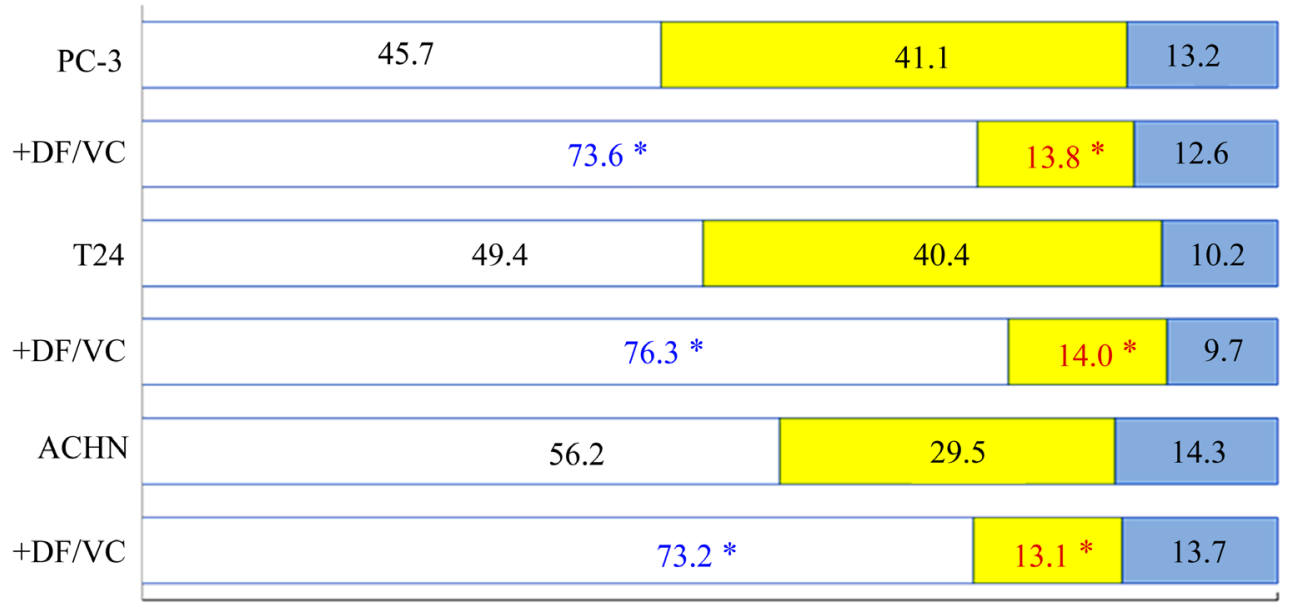

0

$\%$ of Cells in Each Cell Cycle Phase

Figure 4. Cell cycle analysis. PC-3, T24, and ACHN cells were cultured with combination of DF (300 $\mu \mathrm{g} / \mathrm{ml})$ and VC $(200 \mu \mathrm{M})$ for $24 \mathrm{~h}$ and subjected to cell cycle analysis. The cell populations (\%) in specific cell cycle phases are shown as only the mean values from three separate experiments ( $\mathrm{P}<$ 0.05 compared with respective controls). 


\section{$\underline{\text { PC-3 }} \quad \underline{+\mathrm{DF} / \mathrm{VC}}$}

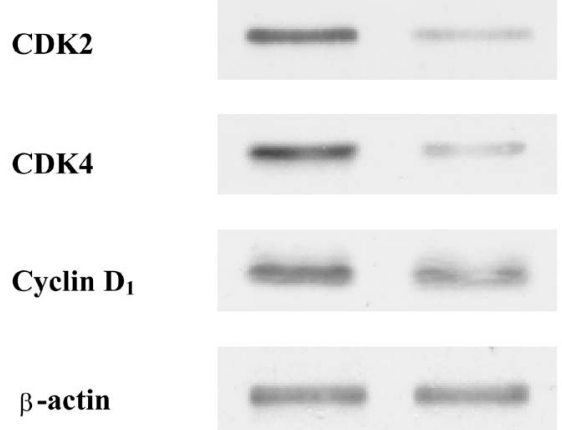

Figure 5. Western blot analysis. After PC-3, T24, and ACHN cells were treated with or without combination of DF (300 $\mu \mathrm{g} / \mathrm{ml})$ and VC $(200 \mu \mathrm{M})$ for $24 \mathrm{~h}$, the expressions of CDK2, $\mathrm{CDK} 4$, and cyclin $\mathrm{D}_{1}$ were analyzed on western blots. Only expressions of these regulators in PC-3 cells are shown here but exactly the same expression patterns were observed in T24 and ACHN cells. Additionally, $\beta$-actin is shown as a protein loading control.

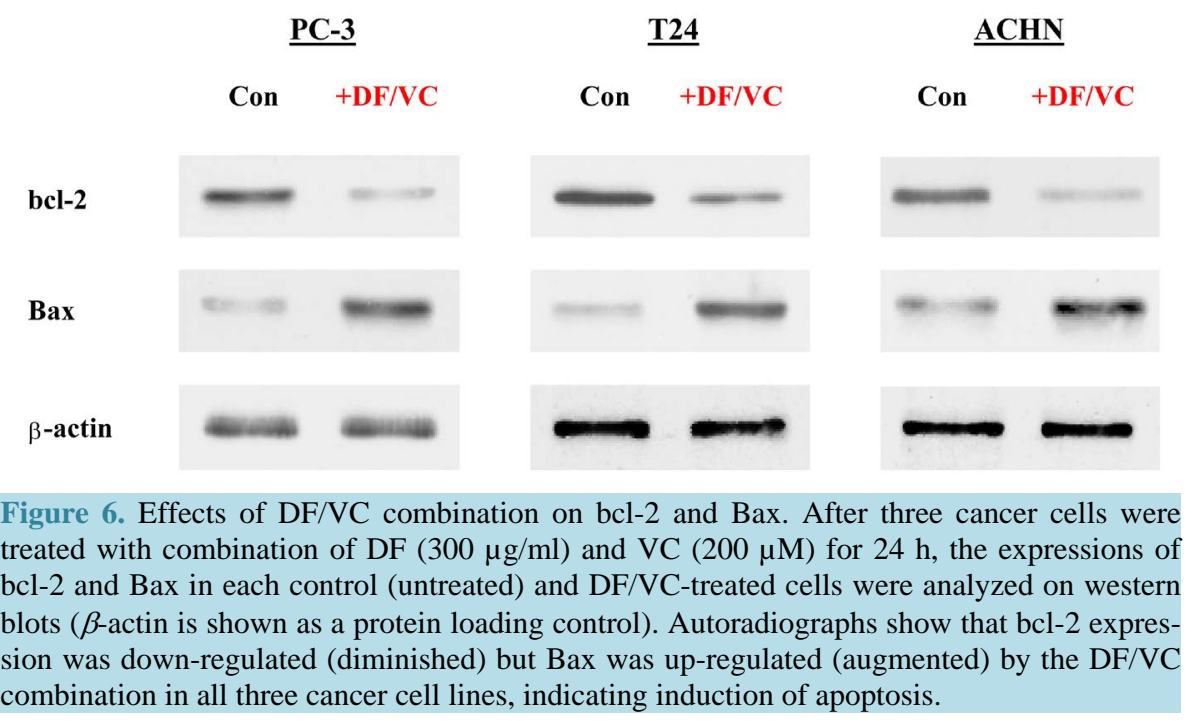

regulator [23], the down-regulation of bcl-2 concomitant with the up-regulation of Bax more likely indicates induction of apoptosis. Therefore, the drastically reduced cell viability with the DF/VC combination is presumably attributed to apoptotic cell death.

\section{Discussion}

We investigated the possible chemosensitizing effect of bioactive $D F$ extracted from maitake mushroom, sensitizing or improving the poor activity/efficacy of chemotherapeutic drugs, on the three urologic cancer cell lines in vitro. As DF has been shown to have antitumor activity with few side effects [14] [15], it appeared to be an appropriate agent for such a combination study. The three chemotherapeutic drugs being currently used in the clinical settings, paclitaxel (PTX), cisplatin (CPL), and 5-fluorouracil (5FU), were first tested for their anticancer effects on prostate cancer PC-3, bladder cancer T24, and kidney cancer ACHN cells, respectively. None of drugs at given concentrations (being the physiologically tolerable levels) was found to have any effects on cell viability of any cancer cells. However, when each drug was combined with DF (300 $\mu \mathrm{g} / \mathrm{ml})$, there was the significant reduction in cell viability of all three cancer cells (Figure 2). These results suggest that DF is capable of sensitizing drugs and enhancing their (poor) anticancer activities to some extent. Thus, it is plausible that DF may have a chemosensitizing effect on (certain) chemotherapeutic drugs. 
As it has been postulated that VC could enhance the bioactivity of DF [18] or its anticancer activity, this possibility was then tested in three cancer cells. At the same time, combinations of three drugs (PTX, CPL, and 5FU) and VC were also examined for any improved anticancer activities on respective cancer cells. We found that the specific combination of DF (300 $\mu \mathrm{g} / \mathrm{ml})$ and VC $(200 \mu \mathrm{M})$ was highly potent, leading to a drastic $\geq 90 \%$ cell viability reduction in all three cancer cells in merely $24 \mathrm{~h}$ (Figure 3). On the other hand, none of drugs' anticancer activities was enhanced with VC, or drug/VC combinations showed no improved anticancer effects. Thus, although VC by itself may not have a chemosensitizing effect on these drugs, once VC is combined with DF, they become very potent and eventually induce a profound cell viability reduction in all three urologic cancer cells. This dramatic impact created by the DF/VC combination appears to result from "synergism" or a synergistic potentiation where DF and VC may work synergistically to exert such a potent anticancer effect on these cancer cells.

To have an insight into the anticancer mechanism of DF/VC combination, its possible effects on the cell cycle regulation were examined. Cell cycle analysis indicated that the DF/VC combination had induced a $\mathrm{G}_{1}$ cell cycle arrest [22], a blocking of the $\mathrm{G}_{1}$-S phase progression that can subsequently lead to a cessation of cell proliferation. Additionally, all three $\mathrm{G}_{1}$-specific regulators, $\mathrm{CDK} 2$, CDK4, and cyclin $\mathrm{D}_{1}$, were significantly down-regulated or their expressions were significantly reduced/diminished by the DF/VC combination in all three cancer cells. This finding further confirms that the DF/VC combination may directly target cell cycle, particularly at the $\mathrm{G}_{1}-\mathrm{S}$ phase transition point.

Lastly, it was not only interesting but also critical to address whether a drastic viability reduction by the $\mathrm{DF} / \mathrm{VC}$ combination could be associated with apoptosis. We then found that the DF/VC combination led to the down-regulation of anti-apoptotic bcl-2 concomitant with the up-regulation of pro-apoptotic Bax in all 3 cancer cells (Figure 6), indicating induction of apoptosis [23]. Therefore, the severe cell viability reduction induced by the DF/VC combination is primarily attributed to apoptotic cell death.

After all, although DF appears to be a promising natural agent for a potential clinical utility, its safety needs to be also addressed. DF is a bioactive extract of maitake mushroom, which is a tasty, edible, medicinal mushroom that has been used dietetically or therapeutically for centuries in Japan and China. Additionally, the US Food and Drug Administration (FDA) has exempted DF from a Phase I study of toxicology and also approved it for the Investigational New Drug (IND) application for a Phase II pilot study on advanced cancer patients [24]. Thus, the safety of DF is granted without any potential side effects.

It should yet bear in mind that this study is the in vitro study, which is unable to show the actual efficacy (of DF) under the physiological condition or in animals or humans. Although DF could be safe, its potential adverse effects must be also closely monitored or assessed in animals prior to a clinical trial. Hence, the next phase of our study is to perform the in vivo study using animals to assess the actual efficacy, effective dosage, and safety of DF (in combination with VC), and such a study may provide us with valuable information on the future plan.

\section{Conclusion}

The present study demonstrates that D-fraction (DF) is a bioactive mushroom extract with a chemosensitizing effect and potent anticancer effect especially once combined with VC. Although DF is capable of enhancing anticancer activities of three chemotherapeutic drugs tested, the DF/VC combination is far superior to any drugs alone or any combinations of drugs and DF (or VC). Such a potent anticancer effect is primarily associated with induction of a $G_{1}$ cell cycle arrest and apoptosis. Therefore, DF may have a great potential as an adjuvant agent that can be combined with certain chemotherapeutic drugs or with VC for the safer and more effective therapeutic options for human urologic cancers as well as possibly other malignancies.

\section{Acknowledgements}

We thank Mike Shirota (Mushroom Wisdom, Inc.) for a kind gift of D-fraction. This work was supported by a research grant from the "Seize the Ribbon".

\section{References}

[1] Jemal, A., Siegel, R., Ward, E., Hao, Y., Xu, J. and Thun, M.J. (2009) Cancer Statistics 2009. CA: A Cancer Journal for Clinicians, 59, 225-249. http://dx.doi.org/10.3322/caac.20006

[2] Mimeault, M., Mehta, P.P., Hauke, R., et al. (2007) Improvement of Cytotoxic Effects Induced by Mitoxantrone on Hormone-Refractory Metastatic Prostate Cancer Cells by Co-Targeting Epidermal Growth Factor Receptor and Hed- 
gehog Signaling Cascades. Growth Factors, 25, 400-416. http://dx.doi.org/10.1080/08977190801930935

[3] Di Lorenzo, G. and De Placido, S. (2006) Hormone Refractory Prostate Cancer (HRPC): Present and Future Approaches of Therapy. International Journal of Immunopathology and Pharmacology, 19, 11-34.

[4] Kamel, M.H., Moore, P.C., Bissada, N.K. and Heshmat, S.M. (2012) Potential Years of Life Lost Due to Urogenital Cancer in the United States: Trends from 1972 to 2006 Based on Data from the SEER Database. Journal of Urology, 187, 868-871. http://dx.doi.org/10.1016/j.juro.2011.10.142

[5] Kaufman, D.S., Shipley, W.U. and Feldman, A.S. (2009) Bladder Cancer. Lancet, 374, 239-249. http://dx.doi.org/10.1016/S0140-6736(09)60491-8

[6] Pow-Sang, J.M. and Seigne, J.D. (2000) Contemporary Management of Superficial Bladder Cancer. Cancer Control, 7, 335-339.

[7] Jemal, A., Murray, T., Ward, E., et al. (2005) Cancer Statistics 2005. CA: A Cancer Journal for Clinicians, 55, 10-30. http://dx.doi.org/10.3322/canjclin.55.1.10

[8] Jacobsohn, K.M. and Wood, C.G. (2006) Adjuvant Therapy for Renal Cell Carcinoma. Seminars in Oncology, 33, 576582. http://dx.doi.org/10.1053/j.seminoncol.2006.06.005

[9] Glaspy, J.A. (2002) Therapeutic Options in the Management of Renal Cell Carcinoma. Seminars in Oncology, 29, 4146. http://dx.doi.org/10.1053/sonc.2002.33083

[10] Jones, J., Juengel, E., Mickuckyte, A., et al. (2009) The Histone Deacetylase Inhibitor Valproic Acid Alters Growth Properties of Renal Cell Carcinoma in Vitro and in Vivo. Journal of Cellular and Molecular Medicine, 13, 2376-2385. http://dx.doi.org/10.1111/j.1582-4934.2008.00436.x

[11] Garcia, J.A. and Danielpour, D. (2008) Mammalian Target of Rapamycin Inhibition as a Therapeutic Strategy in the Management of Urologic Malignancies. Molecular Cancer Therapeutics, 7, 1347-1354. http://dx.doi.org/10.1158/1535-7163.MCT-07-2408

[12] Inamoto, T. and Azuma, H. (2012) Immunotherapy of Genitourinary Malignancies. Journal of Oncology, 2012, 1-8. http://dx.doi.org/10.1155/2012/397267

[13] Mizuno, T. and Zhuang, C. (1995) Maitake, Grifola frondosa: Pharmacological Effects. Food Reviews International, 11, 135-149. http://dx.doi.org/10.1080/87559129509541024

[14] Adachi, K., Nanba, H. and Kuroda, H. (1987) Potentiation of Host-Mediated Antitumor Activity in Mice by $\beta$-Glucan Obtained from Grifola frondosa (Maitake). Chemical and Pharmaceutical Bulletin (Tokyo), 35, 262-270. http://dx.doi.org/10.1248/cpb.35.262

[15] Hishida, I., Nanba, H. and Kuroda, H. (1988) Antitumor Activity Exhibited by Orally Administered Extract from Fruit Body of Grifola frondosa (Maitake). Chemical and Pharmaceutical Bulletin (Tokyo), 36, 1819-1827. http://dx.doi.org/10.1248/cpb.36.1819

[16] Suzuki, I., Hashimoto, K., Oikawa, S., Sato, K., Osawa, M. and Yadomae, T. (1989) Antitumor and Immunomodulating Activities of a Beta-Glucan Obtained from Liquid-Cultured Grifola frondosa. Chemical and Pharmaceutical Bulletin (Tokyo), 37, 410-413. http://dx.doi.org/10.1248/cpb.37.410

[17] Pyo, P., Louie, B., Rajamahanty, S., Choudhury, M. and Konno, S. (2008) Possible Immunotherapeutic Potentiation with D-Fraction in Prostate Cancer Cells. Journal of Hematology and Oncology, 1, 25-33. http://dx.doi.org/10.1186/1756-8722-1-25

[18] Morishige, F. (1986) The Role of Vitamin C in Tumor Therapy (Human). In: Meyskens Jr., F.I. and Parasad, K.N., Eds., Vitamins and Cancer: Human Cancer Prevention by Vitamins and Micronutrients, Humana Press, Clifton, 399-427.

[19] Mordente, J.A., Konno, S., Chen, Y., Wu, J.M., Tazaki, H. and Mallouh, C. (1998) The Effects of Brefeldin A (BFA) on Cell Cycle Progression Involving the Modulation of the Retinoblastoma Protein (pRB) in PC-3 Prostate Cancer Cells. Journal of Urology, 159, 275-279. http://dx.doi.org/10.1016/S0022-5347(01)64081-3

[20] Ullah, M.F., Bhat, S.H., Hussain, E., Abu-Duhier, F., Ahmad, A. and Hadi, S.M. (2012) Ascorbic Acid in Cancer Chemoprevention: Translational Perspectives and Efficacy. Current Drug Targets, 13, 1757-1771. http://dx.doi.org/10.2174/138945012804545669

[21] Chen, Q., Espey, M.G., Krishna, M.C., Mitchell, J.B., Corpe, C.P., Buettner, G.R., et al. (2005) Pharmacologic Ascorbic Acid Concentrations Selectively Kill Cancer Cells: Action as a Pro-Drug to Deliver Hydrogen Peroxide to Tissues. Proceedings of the National Academy of Sciences of the United States of America, 102, 13604-13609. http://dx.doi.org/10.1073/pnas.0506390102

[22] Sherr, C.J. (2000) The Pezcoller Lecture: Cancer Cell Cycle Revisited. Cancer Research, 60, 3689-3695.

[23] Yip, K.W. and Reed, J.C. (2008) Bcl-2 Family Proteins and Cancer. Oncogene, 27, 6398-6406. http://dx.doi.org/10.1038/onc.2008.307

[24] Maitake Products, Inc. (1998) D-Fraction Obtained IND for Clinical Study. Corporate Publication, Paramus. 
Scientific Research Publishing (SCIRP) is one of the largest Open Access journal publishers. It is currently publishing more than 200 open access, online, peer-reviewed journals covering a wide range of academic disciplines. SCIRP serves the worldwide academic communities and contributes to the progress and application of science with its publication.

Other selected journals from SCIRP are listed as below. Submit your manuscript to us via either submit@scirp.org or Online Submission Portal.
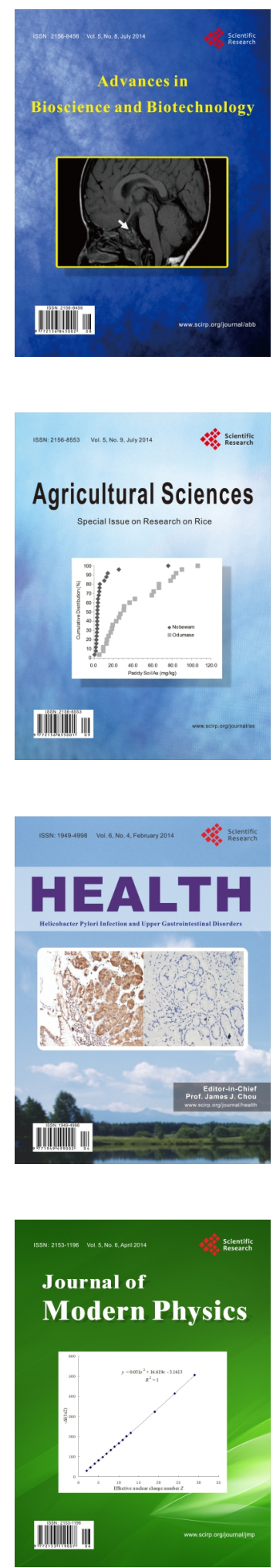
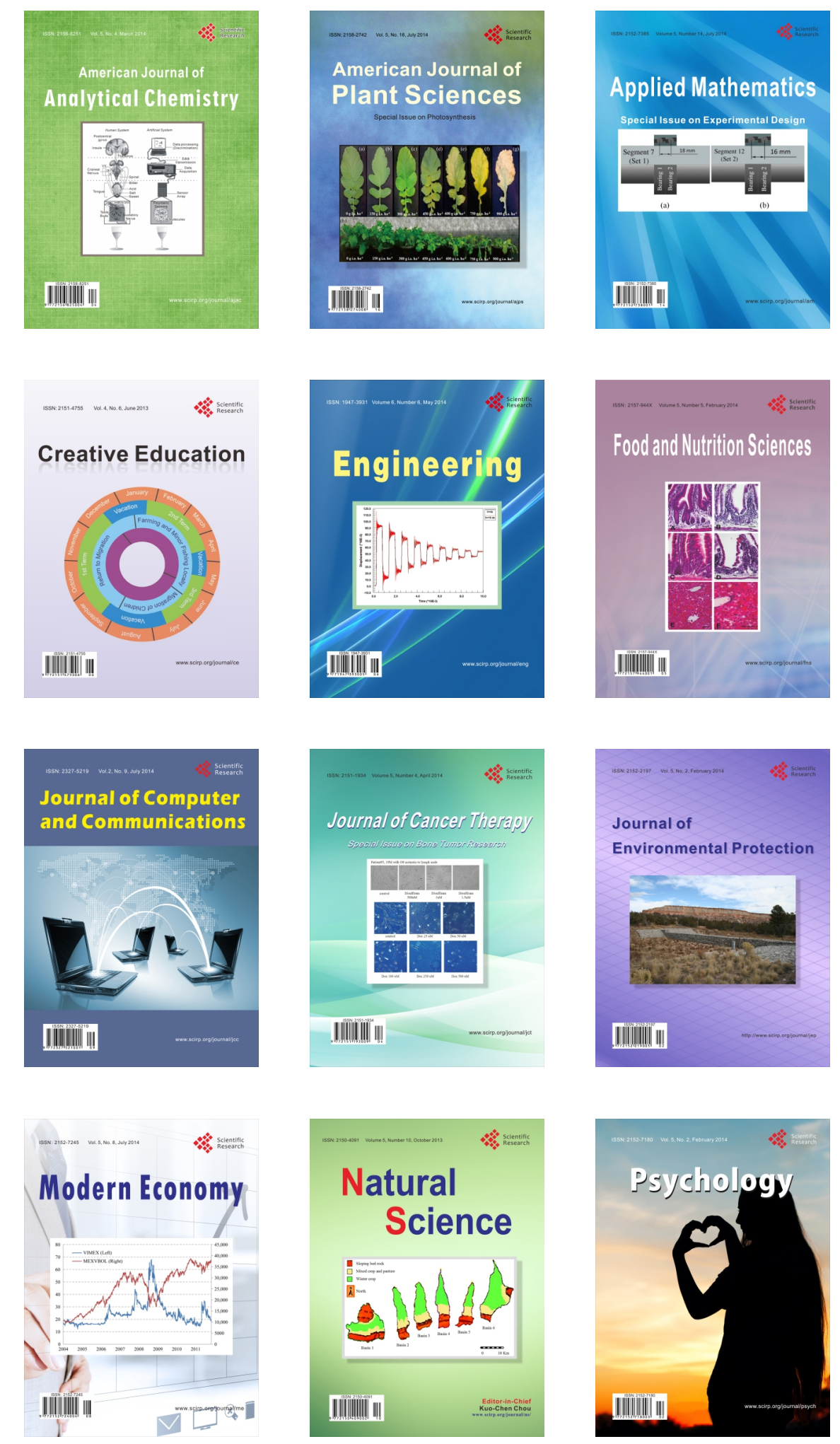